\title{
Epidemiological Review of Spinal Cord Injury due to Road Traffic Accidents in Latin America
}

\author{
Laura Lucía Fernández Londoño ${ }^{a}$ Nicolò Marchesini ${ }^{b}$ Deyer Espejo Ballesteros ${ }^{a}$ \\ Laura Álzate García ${ }^{a}$ Johanna Alejandra Gómez Jiménez ${ }^{a} \quad$ Elizabeth Ginalis ${ }^{c}$ \\ Andrés M. Rubiano d, e \\ anstitute of Neuroscience and Neurosurgery, Faculty of Medicine, El Bosque University, Neurosurgery Research Group, \\ INUB-MEDITECH, El Bosque University, Bogotá, Colombia; 'bepartment of Neurosciences, Biomedicine and Movement, \\ Section of Neurosurgery, University of Verona, Verona, Italy; ' Department of Neurosurgery, Rutgers-Robert Wood

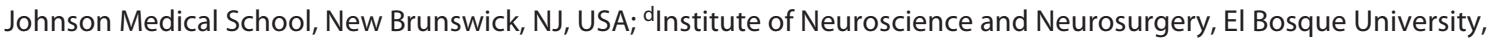 \\ Bogotá, Colombia; ${ }^{\mathrm{e} M E D I T E C H ~ F o u n d a t i o n, ~ C a l i ~ V a l l e, ~ C o l o m b i a ~}$
}

\section{Highlights of the Study}

- Road traffic accidents seem to be responsible for most cases of traumatic spinal cord injury in Latin America, while gunshot wounds and falls represent the most frequent cause in some countries.

- Studies specifically addressing this topic are scarce, heterogeneous, and include only a minority of Latin American countries.

- Registries for data collection on this condition are desirable.

\section{Keywords}

Spinal cord injury · Epidemiology · Traffic accidents · Latin America · South America

\begin{abstract}
Spinal cord injury $(\mathrm{SCl})$ is a disease that affects the normal function of the spinal cord. Road traffic accidents (RTAs) represent the main cause of $\mathrm{SCl}$ worldwide. $\mathrm{SCl}$ may generate physical disability and economic dependency, which is especially significant in low- and middle-income countries such as most of the Latin American countries. The main objective of this study was to present an epidemiological re-
\end{abstract}

karger@karger.com www.karger.com/mpp

Karger $\stackrel{\text { ' }}{5}$
(C) 2021 The Author(s)

Published by S. Karger AG, Basel

This is an Open Access article licensed under the Creative Common Attribution-NonCommercial-4.0 International License (CC BY-NC) (http://www.karger.com/Services/OpenAccessLicense), applicable to the online version of the article only. Usage and distribution for commercial purposes requires written permission. view of SCl secondary to RTAs. Stronger evidence on this condition in Latin America is important for future-specific data collection and prevention strategies. A literature review was carried out using specific search strategies in databases of indexed journals from the period 2000 to 2019. Data on SCI secondary to RTAs in the Latin American region were collected and analyzed. After initial screening and removal of duplicates, 16 articles met the inclusion criteria and were chosen for analysis. Data from 7 Latin American countries were retrievable. On average, RTAs were responsible for $40.81 \%$ of $\mathrm{SCl}$. Data from different studies are heterogeneous. Car accidents and moto accidents were equally responsible for SCls (50.61\% vs. $49.06 \%$ ). The thoracic 
segments were the most commonly affected (57.87\%). Males in their 30 s were the most affected category (76.6\%). $\mathrm{SCl}$ due to RTAs may represent a severe but preventable condition that affects mostly men in their productive age, generating important social and economic issues. Data about this condition in Latin America are scarce, and could limit prevention and treatment strategies. Prospective data collection about this condition is recommended.

(c) 2021 The Author(s).

Published by S. Karger AG, Basel

\section{Introduction}

Traumatic spinal cord injury (SCI) is a multifactorial condition derived from forceful mechanisms, penetrating injuries, or abrupt movements to the spinal structures. It can occur during road traffic accidents (RTAs), falls, sports, physical aggression, and work accidents, among others [1-7]. Trauma is responsible for approximately 15-41 cases of SCI per million inhabitants annually worldwide, and the population between 15 and 35 years of age is the most affected [1,3,8-10]. According to the literature, motor vehicle accidents are responsible for up to $50 \%$ of traumatic SCI cases $[3,11]$.

In low (LICs)- and middle (MICs)-income countries (LMICs), trauma patient costs are estimated to be about 100 billion dollars annually [12]. The World Health Organization has commented that "if the effectiveness of preventive actions is not increased, then road traffic injuries will continue to increase as well and will become a global public health crisis" [12-14]. Although multidisciplinary interventions have been implemented worldwide to reduce morbidity and mortality due to traumatic SCI, the prognosis can remain poor with tremendous social and economic costs $[1,7,15-20]$.

Most data on the epidemiology of traumatic SCI derive from the USA and Canada, and information from other countries of the world is lacking, especially from LMICs [21]. It is estimated that 79,412 new persons are affected each year in Latin America [22].

Given that SCI due to RTAs is a potentially preventable condition, we feel the necessity to fill this lack of data in the Latin American region [8, 22-24]. This information could be helpful to define interventions and allocate resources to reduce the incidence, morbidity, and mortality of traumatic SCI in this region [25].

A literature review on traumatic SCI due to RTAs in Latin America was carried out using the following databases: Pubmed, LILACS, Scielo, Google Scholar, SCOPUS,
Table 1. Categorization of MeSH terms used for the database search

\begin{tabular}{llll}
\hline Region & Injury & Scenario & Statistics \\
\hline Latin America & Spinal cord injury & Traffic accidents & Demography \\
Central America & Spinal cord trauma & Epidemiology \\
South America & & \\
The Caribbean & & \\
\hline
\end{tabular}

ClinicalKey, and ScienceDirect. All articles published between 2000 and 2019 were included for review. The MeSH terms used in the present study are categorized in the main groups listed in Tables 1 and 2 .

\section{Inclusion Criteria}

Studies were included if they addressed epidemiological data of traumatic SCI in any Latin American country or countries, and contained data on spinal cord trauma secondary to RTAs in the Latin American region. Articles that were written in any language and published during 20002019 were included.

\section{Exclusion Criteria}

Studies were excluded if they (1) were published before the year 2000, (2) were not available in full-text format despite meeting the other inclusion criteria, (3) did not include data from Latin American countries, (4) reported on injuries other than traumatic SCI, and (5) published data on RTAs that did not include SCI.

\section{Study/Source of Evidence Selection}

This review was conducted following the SANRA scale for the quality assessment of narrative review articles. Following the search, all identified citations were uploaded into the Microsoft Excel for Office 365 format. Four researchers (L.F., D.E., L.A., and J.G.) independently assessed the relevance of each study by following the inclusion and exclusion criteria. The characteristics of the study (country, study period, and sample size) and the characteristics of the patients (age at presentation of SCI, mechanism of trauma, level of injury, and sex) were collected and tabulated. Full-text studies that did not meet the inclusion criteria were excluded. Any disagreements that arose between the researchers during either title and abstract screening or full-text screening were resolved through discussion [26].
12

Med Princ Pract 2022;31:11-19 DOI: $10.1159 / 000520112$
Fernández Londoño et al. 
Table 2. Specific MeSH terms used for the database search

MeSH terms

Accidental falls/statistics and numerical data

Accidents, traffic/statistics and numerical data

Adolescent

Adult

Middle aged

Brazil/epidemiology

Female

Male

Sex factors

Motorcycles

Patient admission/statistics and numerical data

Spinal cord injuries/epidemiology

Spinal cord injuries/mortality

Transportation of patients

Prevenção

Neurosurgery

Spinal fractures

Mortality

Traumatology
Age factors

Cohort studies

Databases, factual/statistics and numerical data

Disabled persons

Incidence

Life expectancy

Prevalence

Spinal cord injuries/diagnosis

Spinal cord injuries/therapy

Global health

Regression analysis

Spinal cord injuries/etiology

World Health Organization

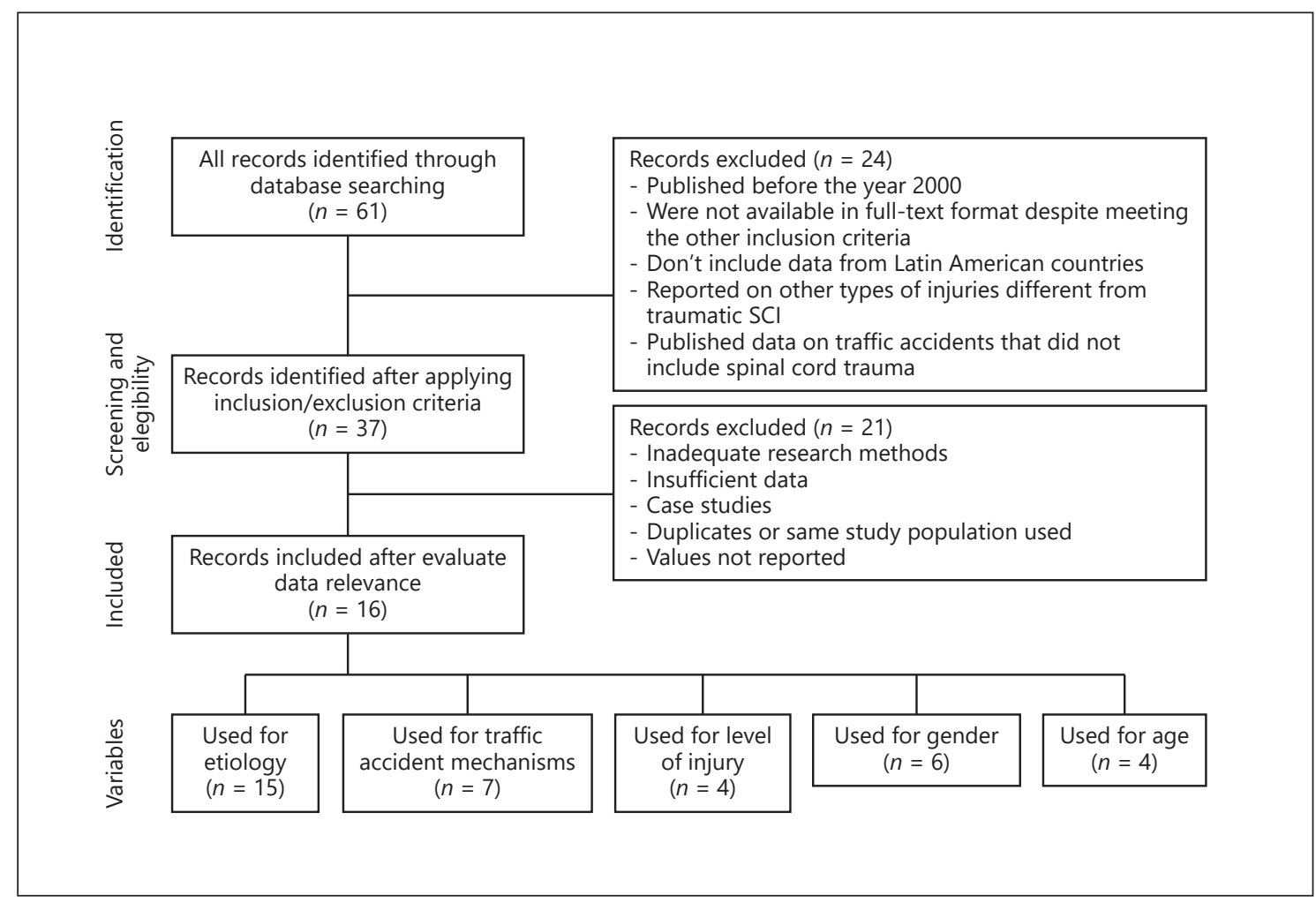

Fig. 1. Flowchart depicting the search strategy adopted to select the papers.

Spinal Cord Injury due to Road Traffic Accidents in Latin America
Med Princ Pract 2022;31:11-19

DOI: $10.1159 / 000520112$ 


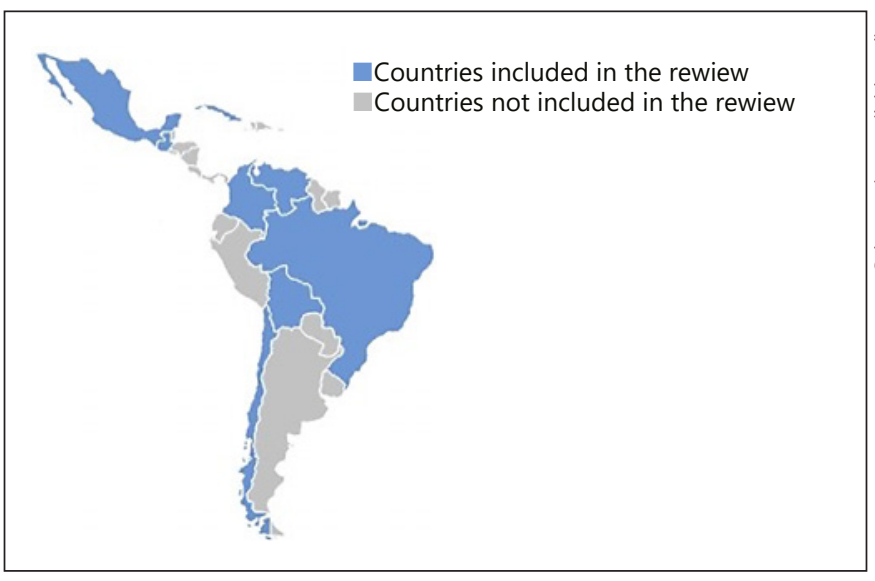

Fig. 2. Latin American countries included in studies from the literature review.

\section{Data Extraction and Statistical Analysis}

After retrieval of relevant studies, data were extracted according to the following variables: (1) etiology of SCI, (2) RTA mechanisms, (3) spinal level of injury, (4) gender, and (5) age. Statistical analysis (percentages, means, standard deviations, and ranges) was performed using Microsoft Excel for Office 365.

After the removal of duplicates, 61 articles were retrieved for screening. Ultimately, 16 articles met the inclusion criteria and were chosen for analysis (Fig. 1). These 16 articles provided data on 7 countries in Latin America (Fig. 2).

\section{Etiology of SCI in Latin America}

Fourteen studies reported on the etiology of SCI. These studies included a total of 3,690 patient records from health centers in Latin American countries. Six studies were from Brazil [27-32], 3 were from Colombia [11,33,34], 2 from Cuba [3, 35], 1 from Venezuela [36], 1 that registered patients from both Chile and Bolivia separately [37], and 1 from Mexico [38]. Altogether, $40.81 \%$ of all patients had a SCI secondary to RTAs. Other causes of SCI included gunshot wounds (21.72\%), falls (21.39\%), sports accident (1.03\%), bladed weapon $(0.29 \%)$, and other (13.43\%).

Of the 6 studies from Brazil, 4 studies reported that the most common cause of SCI was RTAs. The remaining 2 found that falls were the most prevalent cause. In Colombia, of the 3 studies found, 2 reported that the most common cause was gunshot wounds, and 1 study cited falls as the most prevalent cause. In Venezuela, gunshot wounds were the most frequent cause of SCI in 1 study. Of the 2 studies in Cuba, one of them reported RTAs as the most prevalent cause, while the other 1 found that RTAs and falls were equally responsible. The study that presented data from both Bolivia and Chile concluded that the most common causes were due to work accidents in Chile and falls in Bolivia. In Mexico, 1 study found that RTAs were the most common cause of SCI. A summary of this data is presented in Table 3 .

\section{Modality of Traffic Accidents in SCI}

Seven studies reported data on the mechanism of RTAs related to SCI, which included automobile accidents, motorcycles, pedestrian injuries, and other means of transport (bus, truck, and bicycle) [1,28-32,39]. These data are summarized in Table 4. Six of these studies were from Brazil and 1 was from Cuba. These studies included a total of 1,225 SCI patients. According to these data, the vast majority of RTAs involved automobiles (50.6\%) and motorcycles (49.1\%). Pedestrian injuries (0.2\%), and other vehicle modalities including buses, bicycles, etc. were less frequent $(0.1 \%)$.

\section{Level of Injury in SCI due to Traffic Accidents}

Only 4 studies from Brazil reported on the level of SCI $[28,29,39,40]$. These studies included 1,077 patients who suffered SCI due to RTAs in Brazil and classified these cases according to the anatomical level of trauma (Table 5). In the studies conducted by Bittencourt et al. [39] and Praga et al. [38], the cervical spine was most commonly injured (51.4\% and $54.2 \%$, respectively), while in the studies carried out by Oliveira et al. [27] and Barbetta et al. [28], thoracic injury predominated $(52.8 \%$ and $61.3 \%$, respectively). The least frequently injured was at the lumbosacral level in all studies.

\section{Distribution of SCI Secondary to Traffic Accidents according to Gender and Age}

Six articles (1 study from Mexico and 5 from Brazil) were found to report on the gender of patients with SCI RTAs [27-29, 38-40] (Table 6). In all these studies, men composed the majority of SCI cases, with a range of 69.4$87.7 \%$.

Additionally, 4 studies from Brazil were also analyzed for data on the age of patients that was on average 30.2 years [27, 29, 39, 40] (Table 6).

Traumatic spinal injury comprises a variety of damages to the spinal cord and the other components of the spinal column. This can determine instability, pain, impaired mobility, and various grades of neurological impairment. SCI comprises a minority of spinal injuries that leads to neurological deficit. Among the patients re- 


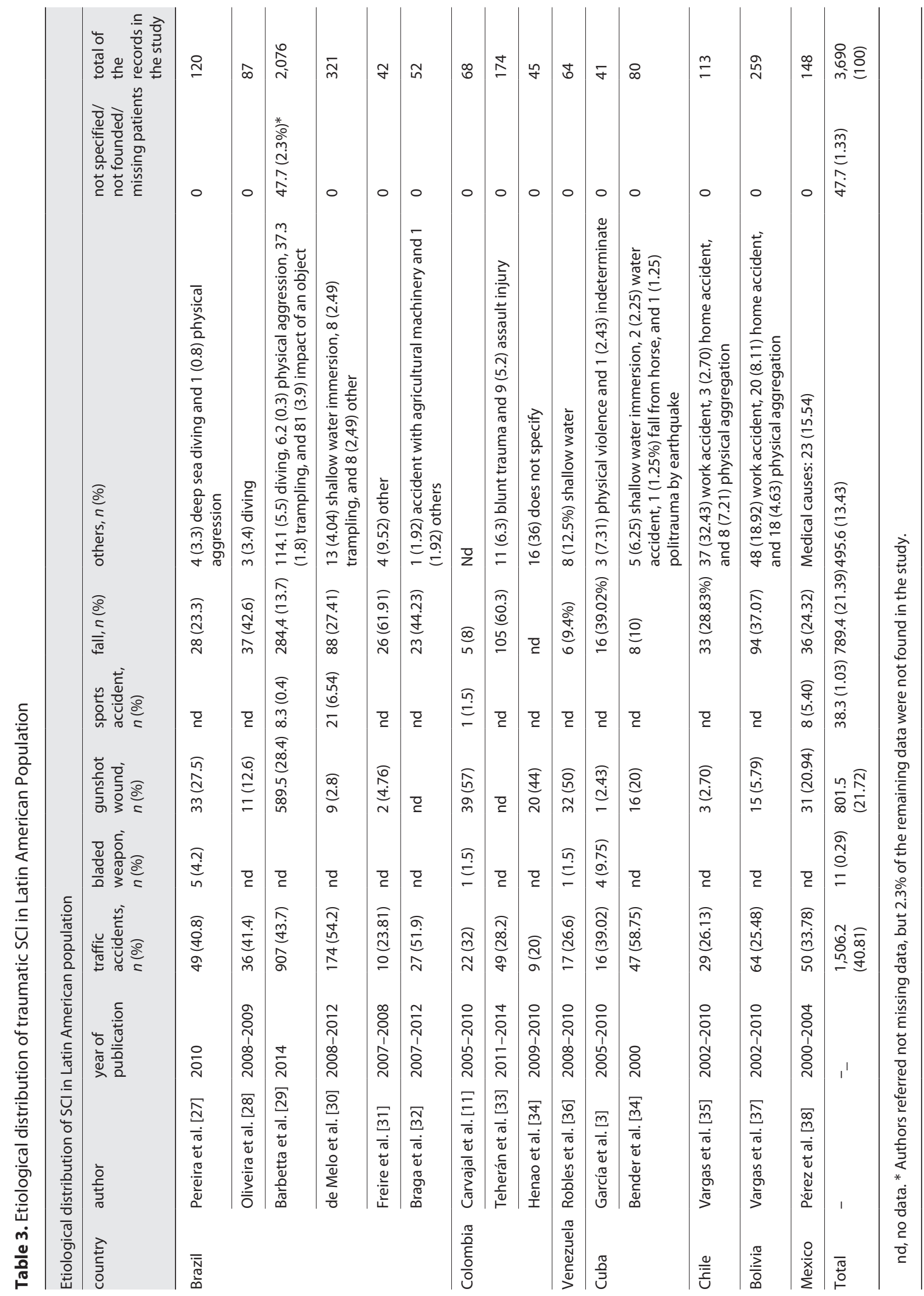


Table 4. Mechanisms of traffic accidents in Latin American patients with SCI

\begin{tabular}{|c|c|c|c|c|c|c|c|}
\hline country & author & year & car, $n(\%)$ & $\begin{array}{l}\text { motorcycle, } \\
n(\%)\end{array}$ & $\begin{array}{l}\text { pedestrian } \\
\text { injuries, } n(\%)\end{array}$ & $\begin{array}{l}\text { bus, truck, bicycle, } \\
\text { and others, } n(\%)\end{array}$ & $\begin{array}{l}\text { all types of traffic } \\
\text { accident, } n(100 \%)\end{array}$ \\
\hline \multirow[t]{4}{*}{ Brasil } & Praga et al. [39] & 2007-2008 & $17(70.83)$ & $5(20.83)$ & $2(8.33)$ & nd & 24 \\
\hline & Oliveira et al. [28] & 2008-2009 & $21(58.33)$ & $15(41.66)$ & nd & nd & 36 \\
\hline & Barbetta et al. [29] & 2014 & 397 (43.77) & $510(56.22)$ & nd & nd & 907 \\
\hline & Braga et al. [32] & 2007-2012 & $12(44.44)$ & $14(51.85)$ & nd & $1(3.70 \%)$ & 27 \\
\hline Cuba & Bender et al. [35] & 2000 & $46(97.87)$ & nd & $1(2.12)$ & nd & 47 \\
\hline Total & - & - & $620(50.61)$ & $601(49.06)$ & $3(0.24 \%)$ & $1(0.08 \%)$ & 1,225 \\
\hline
\end{tabular}

nd, no data.

Table 5. Level of spinal injury in SCl due to traffic accidents in Latin American patients

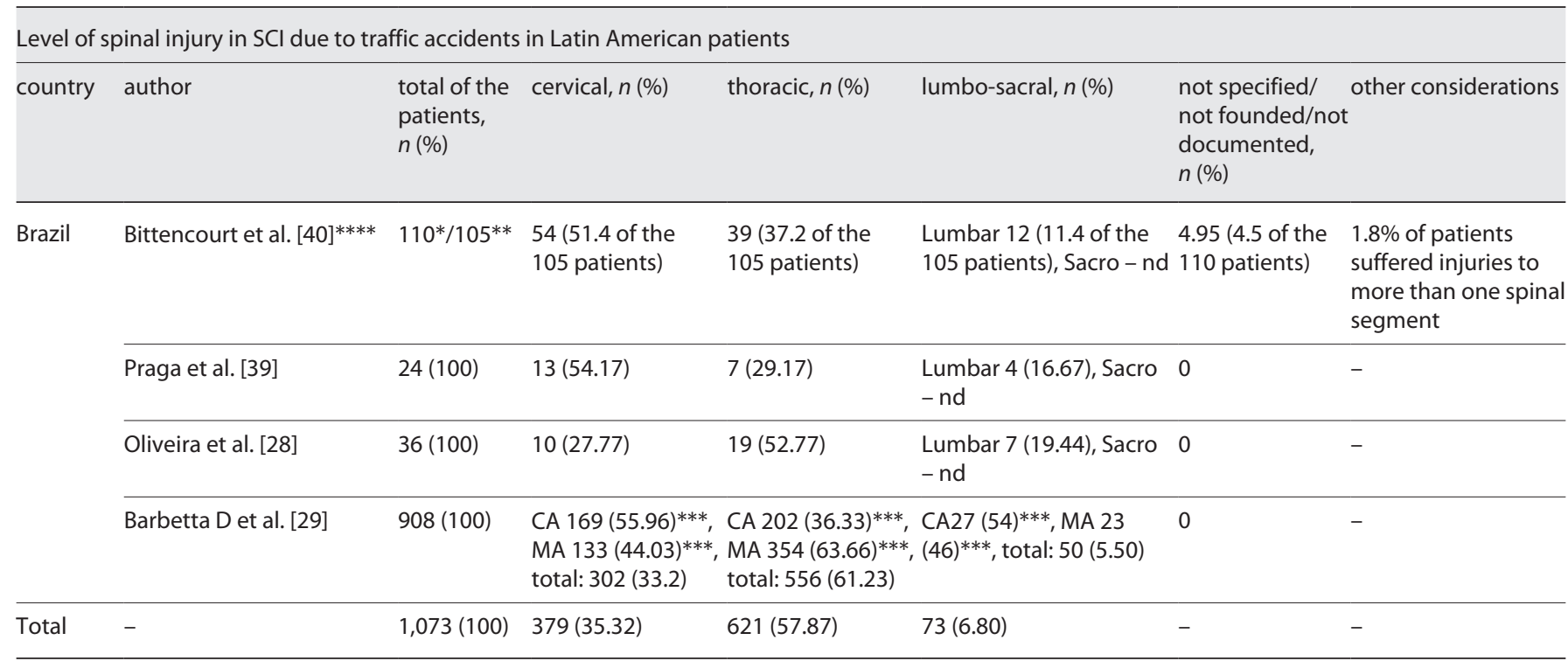

CA, car accident; MA, motorcycle accident; nd, no data. * 110 patients in whom $4.5 \%$ the level of the lesion was not documented. ${ }^{* *} 105$ patients with information on the level of the lesion. ${ }^{* *}(\%)$ percentage of total cervical, thoracic, or lumbo-sacral injuries.

porting a traumatic spinal injury, a large difference exists between the proportion of patients with SCI in high-income countries $(25.27 \%)$ compared to the MICs (36.6\%) and LMICs (70.4\%) [22].

A study by Lee et al. estimated the incidence of SCI in 131 of 178 countries using a population-based regression model, without differentiating the causes of it. Many of these countries included in their analysis lacked highquality studies on this topic. In their study, 23 of 131 total countries were part of the Americas, 3 of these were highincome countries, and 20 were MICs. For MICs, the estimated median incidence of SCI (per million persons) was 22 (range: 13-30). It is important to highlight that in 6 MICs located in the Americas, it was not even possible to estimate these data [41].

Ackery et al. [23] published a review on SCI epidemiology from 17 countries and 6 continents that included high-income countries, LMICs, and LICs. They found 
Table 6. Distribution by gender and age of Latin American patients with SCI due secondary to traffic accidents

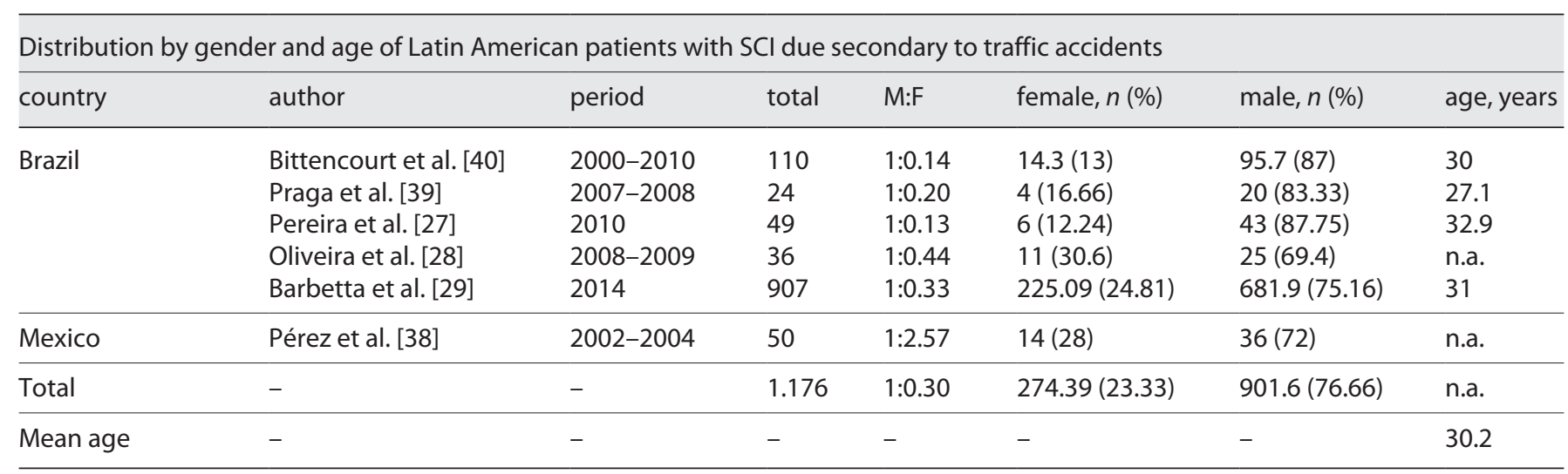

n.a., not available.

that in high-income countries, patients suffering from traumatic SCIs have a longer life expectancy than those in LMICs or LICs. They conclude that injury prevention programs are needed in those areas [23]. This is particularly true in SCI due to RTAs as it most often occurs in the economically productive age-groups (adolescence and young adults), causing serious social and economic issues [25, 42-44]. According to the last Organization for Economic Co-operation and Development list, among the Latin American countries, only Chile, Uruguay, and some Caribbean Islands are classified as high-income countries and not as LMICs [45].

Even before analyzing the results of our study, the lack of homogeneous information about SCI due to RTAs in Latin America is evident. Among the 21 Latin American countries, it was possible to retrieve information from only 7 of them (33.3\%). Notably, even if only one-third of the Latin American countries are represented in this review, around $80 \%$ of the population of Latin America live in these regions.

According to the available literature, RTAs are the most common cause of traumatic SCI worldwide, and one could expect that these results could fit also for the Latin America region [3, 11]. Surprisingly, according to our review, this assumption is not homogeneous in the area. Even in Brazil (where anyway lives around 38\% of the population of Latin America), 2 out of 6 articles reported falls as the most common cause of traumatic SCI $[28,31]$. Nevertheless, these studies comprise a few numbers of patients, and a total of 1,203 out of 2,698 Brazilian patients suffered SCI due to RTAs (44.6\%). Violence seems to be the most relevant cause of traumatic SCI in
Colombia ( 2 out of 3 studies; in none of the studies, RTA was the most common cause) and in Venezuela, and in both countries, the percentage of SCI due to RTAs seems to be up to $32 \%$ of cases. This well correlates with the high rate of homicides, where 27 and 57 homicides per 100,000 inhabitants yearly are reported for Colombia and Venezuela, respectively. We could not compare countries with higher homicide rates (e.g., El Salvador, Honduras) as we did not find studies exploring this topic in these countries [46]. In Chile ( 4 homicides per 100,000 inhabitants yearly), violence seems to be responsible for a negligible proportion of cases, and RTAs follow falls as the second most common cause. In high-income countries, the rate of homicides (and similarly the rate of SCI due to violence) is significantly lower [47].

RTAs remain responsible for most cases in Brazil, Cuba (with percentages reaching almost $59 \%$ of cases), and Mexico. The large number of cases in the Brazilian region of SCI due to RTAs contributes to make this the most relevant cause of traumatic SCI in Latin America; excluding the patients of the Brazilian studies, the number of patients suffering from SCI due to RTAs is 303 out of 992 (30.5\%). We assume that the heterogeneity of the causes of SCI in Latin America is multifactorial and includes demographic, social, and cultural differences among the countries.

Regarding the mechanism of RTAs responsible for SCI, the information was available for only 2 countries (Brazil and Cuba). In Cuba, the vast majority of cases was due to car accidents (almost 98\%), but the number of patients included in the study is small. The results from the Brazilian studies are heterogeneous, as car accidents are 
reported as the most common cause in 3 studies (from $58.33 \%$ to $86.2 \%$ ) and motorcycle in 3 other (from $51.85 \%$ to $80 \%)$. Altogether, in Brazil, $48.7 \%$ of SCI due to RTAs seems to be caused by car collisions and $51 \%$ by motorcycle accidents.

Regarding the level of the lesion, information was available only from Brazilian studies. Two studies found the cervical spine as the most affected, while other studies found it was the thoracic one. In all studies, the lumbosacral region was the least commonly affected. These data are consistent with other studies that confirm the cervical and thoracic regions as the most vulnerable to road traffic collision $[4,8,48]$. Notably, only one of these studies (i.e., the study with the larger number of patients) correlates the exact mechanism of road accident and the level of injury, finding a higher proportion of cervical injuries in car accidents and of thoracic injuries in moto vehicle collisions [29].

The available literature reports that males are more affected than females by SCI due to RTAs and our results confirm these data, even if this information was available only from Brazil and Mexico (76.7\%). Notably, in none of the study, females were more affected than male, and only in 1 study, the proportion of affected females reached 30\% [28].

Regarding age, it has been described that SCI due to RTAs most commonly affects the economically active young population between the ages of 15-35 years. The data in our review also confirm these results in Brazilian studies.

The results of our study demonstrate the lack of information about traumatic SCI due to RTAs in the Latin American region, even if this is considered the most common cause of traumatic SCI worldwide. Only a few studies from a small number of countries focus on this topic, they are often small series of cases, and they generally provide insufficient demographic and clinical data.

This paucity of information precludes a real understanding of the phenomena and the consequent development of prevention and action strategies. These may include legislative interventions (i.e., to stimulate the use of helmets and seat belts or to contrast the use of cell phone or alcohol intake when driving), enforcement (i.e., increase of policy enforcement), public awareness/educational policies, speed control, and road condition improvement [49]. The development of high-quality prospective clinical registries about this condition is desirable.

Our review was limited by the lack of sufficient studies for a more complete and complex analysis on several Latin American countries. Most of the collected data were from Brazilian studies, so it should be noted that the rest of Latin American countries have insufficient or no data on SCI associated with the analyzed variables. For most of the analyzed countries, only 1 study was available. This generates selection bias, and these data therefore may not be extrapolated to other countries of Latin America.

\section{Conclusions}

RTAs are one of the leading causes of SCI in the Latin American population. SCI due to this specific cause is a condition that mostly affects men in their early adult age. The cervical and thoracic spine are the most commonly affected regions. However, data available on SCI in Latin America and specifically those secondary to RTAs are scarce. The development of clinical registries for prospective data collection about this condition in the region would contribute to a better understanding of the phenomena. These data could be helpful for the development of clinical practice guidelines adjusted to the Latin American context for both prevention measures as for the management and comprehensive monitoring of this condition.

\section{Statement of Ethics}

All authors have adhered to institutional and generally accepted ethical standards. The research was conducted ethically according to the World Medical Association Declaration of Helsinki.

\section{Conflict of Interest Statement}

The authors declare that they have no conflict of interest.

\section{Funding Sources}

There were no funding sources for this work.

\section{Author Contributions}

Laura Lucía Fernández Londoño conceived and designed the analysis, collected the data, performed the analysis, wrote the paper, and critically revised the paper; Nicolò Marchesini performed the analysis, wrote the paper, and critically revised the paper; Deyer Espejo Ballesteros, Laura Álzate García, Johanna Alejandra Gómez Jiménez, and Elizabeth Ginalis conceived and designed the analysis, collected the data, performed the analysis, and wrote the paper; Andrés M. Rubiano conceived and designed the analysis, and critically revised the paper. Dylan Griswold conceived and designed the analysis, collected the data, and critically revised the paper; Andrés Mariano Rubiano conceived and designed the analysis, and critically revised the paper.
18

Med Princ Pract 2022;31:11-19

DOI: $10.1159 / 000520112$
Fernández Londoño et al. 


\section{References}

1 Lopez M, Valencia J. Complications in spinal trauma. Rev CES Mov y Salud. 2013;1:44-51.

2 Ballesteros Plaza V, Marré Pacheco B, Martínez Aguilar C, Fleiderman Valenzuela J, Zamorano Pérez JJ. Spinal cord injury: bibliographic update, physiopathology and initial treatment. Coluna Columna. 2012;11: 73-6.

3 Gómez G, Gutiérrez LG, Mirabal MAB, Pensado EDG. Characterization of patients with spinal cord injury. Rev Cuba Med Mil 2013; 42.

4 Chen Y, Tang Y, Vogel LC, Devivo MJ. Causes of spinal cord injury. Top Spinal Cord Inj Rehabil. 2013;19:1-8.

5 Charry J, Lozano A. Spinal cord injury, literature. Rev Navarra Medica. 2016;22:26-46.

6 Padilla H, Ramos Y, Alvis H, Joaquín ALM. Physiopathology of spinal cord injury. Rev Mex Neurocienc. 2013;19:1-8.

7 Rodriguez A. Lesion of the spinal cord: mechanism of the spinal cord injury. Boletín Del Dep Docencia e Investig IREP. 2004;8:69-73.

8 Rahimi-Movaghar V, Sayyah MK, Akbari H, Khorramirouz R, Rasouli MR, Moradi-Lakeh $\mathrm{M}$, et al. Epidemiology of traumatic spinal cord injury in developing countries: a systematic review. Neuroepidemiology. 2013;41:6585.

9 Sekhon LH, Fehlings MG. Epidemiology, demographics, and pathophysiology of acute spinal cord injury. Spine. 2001;26:S2-12.

10 Kurtzke JF. Epidemiology of spinal cord injury. Neurol Neurocir Psiquiatr. 1977;18(1): 157-91.

11 Carvajal C, Carlos Pacheco CG-R, Calderón J, Carlos Cadavid FJ. Clinical and demographic characteristics of patients with spinal cord injury. Experience of 6 years. Acta Medica Colomb. 2015;40:45-50.

12 Organization Pulmonary Hypertension Association. Injuries caused by traffic and disability; 2011.

13 Cripps RA, Lee BB, Wing P, Weerts E, Mackay J, Brown D. A global map for traumatic spinal cord injury epidemiology: towards a living data repository for injury prevention. Spinal Cord. 2011;49:493-501.

14 Organización Panamericana de la Salud. Estado de la seguridad vial en la Región de las Américas; 2019.

15 Soden RJ, Walsh J, Middleton JW, Craven ML, Rutkowski SB, Yeo JD. Causes of death after spinal cord injury. Spinal Cord. 2000;38: 604-10.

16 Bender del Busto J, Hernández E, Zamora F, Araujo F. Multifactorial of the spinal cord injured. Rev Mex Neurocienc. 2003;4:161-7.

17 Street JT, Noonan VK, Cheung A, Fisher CG, Dvorak MF. Incidence of acute care adverse events and long-term health-related quality of life in patients with TSCI. Spine J. 2015;15: 923-32.
18 Acevedo J, Varón L, Berbeo M, Feo ODR. Physiopathological advances in understanding the traumatic spinal cord injury. Bibliograph Rev. 2008;22:272-81.

19 Castillo A. Acute spinal cord trauma. Rev Mex Anest. 2004;27:169-71

20 Castellano JM. Pre-hospital management of spinal cord injury. Emergencias. 2007;19:25-31.

21 Devivo MJ. Epidemiology of traumatic spinal cord injury: trends and future implications. Spinal Cord. 2012;50:365-72.

22 Kumar R, Lim J, Mekary RA, Rattani A, Dewan MC, Sharif SY, et al. Traumatic spinal injury: global epidemiology and worldwide volume. World Neurosurg. 2018;113:e34563.

23 Ackery A, Tator C, Krassioukov A. A global perspective on spinal cord injury epidemiology. J Neurotrauma. 2004;21:1355-70.

24 da Paz AC, Beraldo PS, Almeida MC, Neves EG, Alves CM, Khan P. Traumatic injury to the spinal cord. Prevalence in Brazilian hospitals. Paraplegia. 1992;30:636-40.

25 Fehlings MG, Tetreault LA, Wilson JR, Kwon BK, Burns AS, Martin AR, et al. A Clinical practice guideline for the management of acute spinal cord injury: introduction, rationale, and scope. Global Spine J. 2017;7:84S-94S.

26 Baethge C, Goldbeck-Wood S, Mertens S. SANRA-a scale for the quality assessment of narrative review articles. Res Integr Peer Rev. 2019;4(1):5

27 Pereira CU, de Jesus RM. Epidemiologia do Traumatismo Raquimedular. JBNC. 2018; 22(2):26-31

28 Oliveira LMB, Chein MB, Marinho SC, Duarte TB. Epidemiological evaluation of victims of spinal cord injury. Rev Col Bras Cir. 2011;38: 304-9.

29 Barbetta DC, Smanioto TR, Poletto MF, Ferreira R, Lopes A, Casaro FM, et al. Spinal cord injury epidemiological profile in the sarah network of rehabilitation hospitals: a Brazilian population sample. Spinal Cord Ser Cases. 2018;4:32.

30 Melo De, Eduarda L, Vidotto L. Characterization and clinical features of operated patients with spinal cord injury. Rev Bras Ortop. 2016; 52:479-90.

31 Freire P, Flávio A. Epidemiological evaluation of thoracic and lumbar fractures treated at the orthopedic and traumatology service of the hospital Getúlio vargas in. Recife. 2009;8: 395-400.

32 Braga CT, Sousa EB, Borges IBC. Epidemiological perfile of patients with thoracic and lumbar fractures operated at the neurosurgery service of the Hospital de Base do Distrito Federal. Brasília-Brasil. 2013;32:19-25.

33 Teherán A, Castro O. Incidence and characteristics of spinal cord injury in a III level hospital. Bogotá 2011 - 2014. Panam J Trauma Crit Care Emerg Surg. 2016;5:140-7.
34 Henao L, Patricia C, Ernesto J, Parra P. Situation and disability of adult patients with spinal cord injury in the city of Manizales. J Health Promot. 2011:52-67.

35 Bender JE, Elizabeth D, González H, Maribel L, Reinaldo P, Araujo F. Clinical characterization of patients with traumatic spinal cord injury. Rev Mex Neurocienc. 2002;3:135-42.

36 Robles JO, Luís ICJ, Roig G, Dra II, Oliva YS, Lianys ID, et al. Epidemiology of traumatic spinal injury. Rev Cuba Med Física y Rehabil. 2012;4:85-94.

37 Vargas A, Cortez S, Vargas V, Vargas MA, Parra G. Epidemialogical features of spinal cord injury: a comparison between Valparaíso-Chile and Cochabamba-Bolivia. Rev Chil Neurocir. 2011;36:20-6.

38 Pérez R, Martín S, Renán S, Ortiz SD. Epidemiological aspects of spinal cord injury of the population of the Centro. Nacional de Rehabilitación. 2008;20:74-82.

39 Praga J. Disability for spinal cord injury due to road traffic accidents. Coluna Columna. 2011;10:175-8.

40 Bittencourt T, Murilo dos Santos S, Oliveira G, Brito R, Santos MGE. Epidemiology of spine fractures in motorcycle accident victims. Coluna Columna. 2016;15:65-7.

41 Lee BB, Cripps RA, Fitzharris M, Wing PC. The global map for traumatic spinal cord injury epidemiology: update 2011, global incidence rate. Spinal Cord. 2014;52:110-6.

42 Guerra SR. Rachimedullar trauma: a short history. Rev Med Electrón. 2011;33:863-8.

43 Scholtes F, Brook G, Martin D. Spinal cord injury and its treatment: current management and experimental perspectives. Adv Tech Stand Neurosurg. 2012;38:29-56.

44 McDonald JW, Sadowsky C. Spinal-cord injury. Lancet. 2002;359:417-25.

45 Low- and middle-income countries n.d. https: //wellcome.org/grant-funding/guidance/ lowand-middle-income-countries accessed 2021 Mar 5.

46 Canudas-Romo V, Aburto JM. Youth lost to homicides: disparities in survival in Latin America and the Caribbean. BMJ Glob Health. 2019 Apr 10;4(2):e001275.

47 Grinshteyn E, Hemenway D. Violent death rates: the US compared with other high-income OECD countries, 2010. Am J Med. 2016 Mar;129(3):266-73.

48 Leal-Filho MB, Borges G, Almeida BR, Aguiar AA, Vieira MA, Dantas KS, et al. Spinal cord injury: epidemiological study of 386 cases with emphasis on those patients admitted more than four hours after the trauma. Arq Neuropsiquiatr. 2008;66:365-8.

49 Staton C, Vissoci J, Gong E, Toomey N, Wafula $R$, Abdelgadir J, et al. Road traffic injury prevention initiatives: a systematic review and metasummary of effectiveness in low and middle income countries. PLoS One. 2016 Jan 6;11(1):e0144971. 